\title{
Justiça de Transição e os Xetá: sem anacronismos
}

\author{
EDILENE COFFACI DE LIMA \\ GIAN CARLO TEIXEIRA LEITE
}

No capítulo "Violação dos Direitos Humanos de Povos Indígenas", no relatório da Comissão Nacional da Verdade, publicado no final de 2014, dez povos indígenas constam como as maiores vítimas da Ditadura brasileira: Cinta-Larga (RO), Waimiri-Atroari (AM), Tapayuna (MT), Yanomami (AM/RR), Panará (MT), Parakanã (PA), Xavante de Marãiwatsédé (MT), Araweté (PA), Arara (PA) e Xetá (PR). A indicação dessas etnias específicas evidentemente não quer sugerir que apenas esses povos tenham sofrido violações, mas sim que esses grupos foram eleitos como emblemáticos da violência perpetrada que, como o sabemos, repetiu-se em todos os quadrantes do país e que apenas pesquisas mais aprofundadas, com o seguimento dos trabalhos da Comissão Nacional da Verdade (CNV) - sugerido, mas não realizado até agora -, poderão qualificar melhor as informações. De norte a sul do Brasil passaram-se situações desse tipo e alguns dos grupos envolvidos em situações de expropriação territorial, ensaiaram ou ainda ensaiam fazer, a partir de muitos esforços, o retorno às suas terras originárias.

Entre os dez grupos mencionados no Relatório da CNV, lá estão os Xetá, o último grupo contatado no Sul no Brasil, na metade do século passado, que viveu o horror da impiedosa cobiça de suas terras pela frente cafeeira, iniciada na Marcha para o Oeste, do período varguista, emendada com o início da Ditadura Militar, a partir de 1964. As razões dessa cobiça não devem surpreender ninguém: invariavelmente os indígenas eram (serão ainda?) tidos como improdutivos e, mais, como entraves ao progresso, apresentados como obstáculos à expansão da fronteira agrícola ou de qualquer outra frente de expansão econômica.

Não deve causar estranheza também que entre esses dez grupos indígenas eleitos no relatório da CNV como "emblemáticos", sejam os Xetá um dos poucos, acompanhados dos Tapayuna (PA), que permanecem desterrados, sem terras demarcadas, estando ambos ainda pleiteando que se faça essa reparação. Do genocídio recuperaram-se, porém não do desterro. 


\section{Exílios índios: Xetá}

São volumosos - funestos talvez exprima melhor o que se quer dizer - os números que atestam o declínio demográfico dos Xetá. Segundo registros escritos, em uma década, 1950, foram reduzidos de aproximadamente 200-250 pessoas para 50 (cf. Fernandes 1958: 31 e 1960). Enfatizamos aqui que se tratam de registros escritos, em virtude do fato de que alguns Xetá dizem que os números eram mais avantajados. Claudemir Xetá, cujo pai, Tikuen, foi retirado criança da Serra dos Dourados e falecido há 15 anos, estima que os Xetá totalizavam aproximadamente 2 mil pessoas.

Em se tratando do café, cumpre mencionar que no início daquela mesma década, uma reportagem da Revista da Guaíra, apresenta a monocultura cafeeira paranaense como aquela que, em comparação a outros estados, vinha apresentando os maiores percentuais de crescimento e produtividade no país. Exaltando o modus operandi de um expansionismo que "se deu de forma rápida, como bem dispõe a nova técnica militar" (Cataldi 1951), a matéria jornalística faz projeções.

Tendo sido o Estado que apresentou maior índice de crescimento demográfico nos últimos 10 anos (76\% segundo dados fornecidos pelo IBGE), é de se prever, nos próximos 10 anos, um progresso jamais alcançado por qualquer outro Estado em qualquer tempo.

Ora, se em uma década (1940-1950), a população paranaense obteve crescimento em cerca de $75 \%$, o tom especulativo e esperançoso que se projeta para os próximos dez anos em nome do progresso só revela a face sombria do desenvolvimentismo, pois, sem surpresas, a redução demográfica dos Xetá mencionada acima - o genocídio para dizer de forma direta - se efetivou justamente neste ambiente ufanista. Cabendo notar que os dados demográficos disponíveis são diametralmente opostos: a pujança de uns é a tragédia de outros.

O crescimento demográfico da população paranaense articulada sinistramente à redução dos Xetá permite-nos retomar aqui um chamamento da escrita de Pierre Clastres que aponta o que há de paradoxal em nossa sociedade. Afinal, no ocidente vigora esse modelo em que é mais destruidora justamente a sociedade que mais exalta e se engaja na produção (Clastres 2014:86). A sociedade que efetivamente mais produz é a que mais destrói. Ao mesmo tempo, é a que menos distribui.

Apesar da consolidação do contato tardio com os brancos, datado de meados do século passado, existem informações esparsas sobre os Xetá desde a metade do século XIX (Mota 2013). Os Xetá estavam então localizados nas imediações da Serra dos Dourados, instalados na margem esquerda do rio Ivaí, afluente do rio Paraná, onde este delimita a fronteira dos estados do Paraná e do atual Mato Grosso do Sul. Vivendo da caça e da coleta, pequenos grupos perambulavam e dispunham seus acampamentos por uma extensa região.

Foi apenas na metade do século passado, quando a frente cafeeira se deslocou do norte para noroeste do estado do Paraná, pressionando o território por onde os pequenos grupos perambulavam, que o contato dos Xetá com os brancos se consolidou e tornou-se irreversível. O projeto varguista de "Marcha para o Oeste", mencionado no início, fazendo avançar a fronteira agrícola da cafeicultura, encerrou qualquer possibilidade de os Xetá darem continuidade à fuga que empreendiam há algum tempo com relativo sucesso. 
A população xetá, acuada diante dos colonizadores, em menos de uma década sucumbiu diante da violência e de diversas mortes, decorrentes de doenças ou envenenamentos, raptos e desaparecimentos, sendo que todos esses termos se confundiam numa trama sinistra. Assim, na documentação restam ainda vários desaparecimentos possíveis de serem identificados na menção a caminhões que se diz saírem da região da Serra dos Dourados carregados com diversos xetás, mas que iam adiante com destino incerto. Cruelmente, um recorte de jornal - para nossa sorte guardado no arquivo da Universidade Estadual de Londrina (UEL) - que menciona um desfile (como um desses desfiles comemorativos de final de campeonato ou coisa que o valha) em que os Xetá foram ostentados, por assim dizer, como troféus, na cidade de Cruzeiro do Oeste (Ubiratan 1994). Em cima de um caminhão, os Xetá foram exibidos vestindo camisetas da empresa colonizadora, a mesma que usurpava suas terras, a COBRIN$\mathrm{CO}$, empresa vinculada ao grupo Bradesco. Uma sombra encobre boa parte da documentação, sem que possamos ainda desfazê-la: justamente o paradeiro desses xetás que foram dali retirados e jamais retornados.

Para que se possa ter uma ideia mais precisa sobre o contexto histórico adverso em que se efetivou o contato dos Xetá, basta lembrar que em 1949 o então governador Moyses Lupion promoveu a redução de diversos terras indígenas kaingang e guarani aqui no Paraná. As informações apresentadas nos trabalhos da Comissão Estadual da Verdade do Paraná dão a dimensão do esbulho. Nela se observa que a partir do que ficou conhecido como Acordo ${ }^{1}$ Lupion, a TI Mangueirinha, que tinha 17.308ha, foi reduzida a 7.400ha; a TI São Jerônimo da Serra, de 33.800ha, passou a 4.840ha; a TI Queimadas, de 26.000ha, passou a 1.700ha; a TI de Marrecas, de 17.019ha a 16.838ha; a TI Ivaí foi reduzia de 36.000ha a 7.200ha; e a TI Boa Vista foi extinta a partir do famigerado Acordo, que mereceria muitas aspas. São salientes os confiscos de terras indígenas que se estenderam por todo o Paraná, um esbulho orquestrado e realizado pelas mãos do próprio Estado.

Vendo a drástica redução territorial, não há como ter dúvida de que esse era sim o pior contexto para se estabelecer o contato com os Xetá, e que pouco se alterou com a substituição de governo, com a entrada de Bento Munhoz da Rocha, que esteve à frente do comando político por meia década, de janeiro de 1951 a abril de 1955. Na sequência, Bento Munhoz da Rocha assumiu o Ministério da Agricultura e um pouco depois foi eleito deputado federal. Enquanto deputado federal (1959-1962), expôs com veemência sua defesa do que então se chamava de "pioneirismo", a ação justamente daqueles que estavam implicados na subtração da vida e do território dos Xetá. Sem meias palavras, bradou na tribuna: "O pioneirismo significa, se não uma exigência de assistência do Governo, pelo menos atitude do Governo no sentido de que não atrapalhe a expansão pioneira” (Munhoz da Rocha apud Gonçalves 1997).

Seja com Bento Munhoz da Rocha, seja com Moysés Lupion, que o sucedeu cumprindo um segundo mandato (de 1956 a 1960), por toda a década de 1950 os apelos para que se garantisse a demarcação de terras aos Xetá não foram ouvidos. Isso aparece em documentos oficiais do então órgão tutor - o Serviço de Proteção aos Índios - ou em outros, elaborados por profissionais da Antropologia, especialmente por José Loureiro Fernandes, o fundador do Departamento de Antropologia na UFPR.

1 Não deve ser coincidência que foi nas duas gestôes (1947-1951 e 1956-1960) de Moysés Lupion que o Paraná mais titulou terras em todo período republicano, totalizando quase 36 mil títulos (cf. Pacheco 2018:219). 
Na década seguinte, nos anos de 1960, com os militares tomando o poder, a situação em nada se altera. A condição desterrada dos Xetá simplesmente passou a ser dada como um fato consumado, como se os Xetá estivessem "rumo à extinção" e, portanto, sem que fosse preciso se comprometer com a reunião dos sobreviventes.

Assim, é preciso notar aqui que no início da década de 1960 - em 30 de maio de 1961 - foi criado o Parque Nacional de Sete Quedas, em parte do qual reservou-se terras aos Xetá. No entanto, jamais se providenciou o retorno dos sobreviventes para o seu território e esses permaneceram dispersos em diferentes localidades (Mangueirinha, Marreca dos Índios, Tamarana, Pinhalzinho). Cabe aqui um parêntese para observar que em pesquisa no acervo do Arquivo Edgard Leuenroth (AEL), na Unicamp, em dezembro de 2018, encontramos uma minuta do projeto de lei que cria o Parque Nacional de Sete Quedas. Talvez seja precipitado dizer, mas a atuação da Associação Brasileira de Antropologia na defesa da criação de áreas reservadas aos indígenas pode ter ali sua primeira expressão, logo interrompida, pois o golpe militar não tardou.

Desde a criação do Parque Nacional de Sete Quedas, passaram-se mais vinte anos e em 04 de junho de 1981 o parque foi extinto pelo Decreto Presidencial 86.071 (Silva 1998:210), no mandato do General João Batista Figueiredo. Em vinte anos, dezessete dos quais sob o domínio dos militares, não foram encaminhadas quaisquer providências para a reunião dos sobreviventes xetá no território que lhes foi destinado.

Ao fim e ao cabo, o Decreto de extinção do Parque Nacional de Sete Quedas encerra qualquer iniciativa de Estado para reunir e assistir os Xetá e põe fim também à própria paisagem natural, dado que o local conhecido como Sete Quedas foi inundado com o início do funcionamento da Usina Hidrelétrica de Itaipu, em 1982, que, na outra ponta, alcançava os índios Avá-Guarani ${ }^{2}$.

Embora poucas vezes esse fato seja notado, com um único Decreto Presidencial foram subtraídos territórios de dois povos indígenas. Os Avá-Guarani que menciono aqui são esses mesmos que, recentemente, tiveram mandato de reintegração de posse autorizando sua retirada do lugar ${ }^{3}$. O interessado em sua retirada é justamente o Estado, através da UHE de Itaipu. Fica claro que não é apenas a iniciativa privada que avança sobre as terras indígenas, há muito o Estado está implicado na violência de desterrar povos. Vemos isso acontecer agora mesmo também com a construção da UHE de Belo Monte. A indiferença, sob a qual se ancora o avanço sobre as terras indígenas, não reconhece matizes ideológicos.

Da redemocratização do país até os dias de hoje a situação em pouco se alterou para os Xetá, que vivem ainda em territórios alheios, a maior parte na TI São Jerônimo da Serra, no município do mesmo nome, onde são minoritários entre os Kaingang e Guarani. De modo direto cumpre repetir as palavras do relatório da CNV: no período da ditadura militar os Xetá foram “jogados no esquecimento" (CNV, vol. 2:220).

2 A história da construção da UHE Itaipu e seus impactos socioambientais são extensamente desenvolvidos na coletânea recém-publicada de D. Mamed, M. Caleiro e R. Bergold (2016). Neste dossiê está abordado no artigo de Júlia Navarra (infra).

3 No Oeste Paranaense, pelo menos até abril de 2019, seis comunidades Avá-Guarani foram ameaçadas de despejo por ações de reintegração de posse movidas pela Itaipu Binacional e pelo Governo Estadual do Paraná (CIMI 2019). 
Totalmente desterrados, vivendo cada um em uma diferente localidade, na década de 1980 sabiase com certeza da existência de apenas quatro (4) xetá, "tirados do mato" " Tikuen, Tuca, Kuen e Ã, a última era então a única mulher. Os dois primeiros faleceram no início deste século, sendo vivos os dois últimos, morando em diferentes localidades: Kuen na Terra Indígena Marrecas e Ã em São Jerônimo da Serra. Nos anos 1990, a partir de esforços da antropóloga Carmen Lúcia da Silva (hoje professora na UFMT), foram localizados mais quatro xetá - os irmãos Rondon e Tiquen e as duas Tiguás (Maria Rosa e Ana Maria), totalizando então oito (8) sobreviventes da Serra dos Dourados. Contabilizados hoje, os Xetá fruto de relações mestiças alcançam quase duas centenas de descendentes que batalham por suas antigas terras, pois, previsivelmente, não lhes satisfaz viverem como pessoas desterradas. Neste momento seu território na Serra dos Dourados (noroeste do Paraná) resta apenas identificado e contestado, seu efetivo reconhecimento e homologação não parece previsto para o futuro próximo.

O contexto político em que se produziu a mortandade e a usurpação do território dos Xetá fazse ainda mais notável quando se observa que a Convenção 107 (que antecedeu a 169), de 05 de junho de 1957, da Organização Internacional do Trabalho foi ratificada pelo Brasil. Em tal Resolução, concernente às Populações Indígenas e Tribais, estava previsto em seu $12^{\circ}$ Artigo:

1. As populações interessadas não deverão ser deslocadas de seus territórios habituais sem seu livre consentimento, a não ser de conformidade com a legislação nacional, por motivos que visem à segurança nacional, no interesse do desenvolvimento econômico do país ou no interesse da saúde de tais populações.

2. Quando, em tais casos, se impuser um deslocamento a título excepcional, os interessados receberão terras de qualidade ao menos igual à das que ocupavam anteriormente e que lhes permitam satisfazer suas necessidades atuais e assegurar seu desenvolvimento futuro. Quando houver possibilidade de encontrar outra ocupação ou os interessados preferirem receber uma indenização em espécie ou em dinheiro, serão assim indenizados com as devidas garantias.

3. As pessoas assim deslocadas deverão ser integralmente indenizadas por toda perda ou dano por elas sofrido em consequência de tal deslocamento.

Ou seja, previa-se tudo o que não foi realizado. Não se deve perder de vista que no ano de 1957, da ratificação da Resolução 107 da OIT, estava em curso o ápice do genocídio dos Xetá, o qual teve continuidade nos anos que se seguiram. Assim, a violência sofrida por eles vai na contramão de tudo o que estava previsto na Resolução 107: foram violentamente deslocados de seu território habitual; não lhes foram garantidas terras em qualquer outro local; sequer se cogitou que devessem ser indenizados por todas as perdas e danos.

4 Fazemos aqui uma pequena nota para observar que os Xetá "tirados do mato" são aqueles que comumente os brancos chamam de "puros" e que lograram dar continuidade ao grupo ao partir da "mistura”, seja com outros povos indígenas do entorno sejam com brancos ou negros, sendo essas últimas uniões menos frequentes. Processos assemelhados viveram outros grupos indígenas desterrados no Brasil, em diferentes regiões, como foi o caso dos Pataxó (Souza 2017), no Nordeste, e dos Avá-Canoeiro, no Centro-Oeste, conforme apresentado por Patrícia Mendonça neste dossiê. 
Olhando para os dias de hoje, não há qualquer esperança quando se aprecia a possibilidade de os Xetá retornarem para suas terras. Essa impossibilidade atual não se deve ao fato de que construíram suas vidas (casaram, tiveram filhos, empregaram-se em meio a outros indígenas ou em meio aos brancos) longe da Serra dos Dourados, mas porque, como que perversamente, a própria legislação opera contra o grupo desde o início deste século.

O maior obstáculo para viabilizar o retorno daqueles que assim o desejam à Serra dos Dourados está no Marco Temporal, um expediente jurídico, gestado no STF por ocasião da demarcação da TI Raposa Terra do Sol. O Marco Temporal prevê que se um dado grupo indígena não estivesse na terra reivindicada exatamente no dia 05 de outubro de 1988, data da promulgação da Constituição Brasileira, por uma perversa ironia, contrariando o que consta da própria Constituição, seu direito seria, por assim dizer, suspenso ou não reconhecido. E mais, se lá não estivessem de peito aberto para defender suas terras, seus direitos simplesmente deixam de existir. Esse é o chamado "renitente esbulho".

Nas palavras de Samuel Barbosa, em livro recentemente publicado (Carneiro da Cunha e Barbosa 2018: 12), "O mecanismo do marco temporal/renitente esbulho cria para os índios o ônus de provar que continuaram resistindo fisicamente ou pelas vias judiciais. Não responde quem praticou o esbulho, mas quem o sofreu". É inequívoca a afirmação do professor de Direito. E assustadora também, pois, como devem notar, estão invertidas as posições e acabamos às voltas com o velho expediente de responsabilizar as vítimas, não os causadores de danos.

Tanto mais arbitrário o Marco Temporal quando se considera que apenas do acervo do SPI, entre os anos de 1950 e 1967, conforme consta de uma recente publicação (Faustino e Mota 2018), existem 487 documentos que atestam a existência dos Xetá e seus sofrimentos durante e após a retirada da Serra dos Dourados. Incluem-se entre os documentos tanto acompanhamento de frequência escolar de Ã e Caiuá quanto a aquisição de roupas e remédios para os Xetá retirados de suas terras. Sem que se tenha até agora pesquisado quantitativamente os acervos distribuídos em diferentes instituições museais de Curitiba, estimamos que não deve ser difícil os documentos alcançarem algo perto de uns mil arquivos, com diferentes fins, considerando tudo o que o professor José Loureiro Fernandes e Vladimir Kozak, principalmente, legaram sobre o grupo.

Fazemos referência aqui tanto aos arquivos de caráter mais acadêmico, quanto às cartas e fotos que ambos espalharam entre diferentes interlocutores. Apenas o acervo documental de Loureiro Fernandes, reunido no Centro de Estudos Bandeirantes, soma mais de 4 mil arquivos. Claro que não são todos relativos aos Xetá - incluem também seus estudos em medicina, ao mesmo tempo que sobre folclore e os Kaingang, entre outros. Se estimarmos que ao menos 1/10 desses documentos sejam relativos

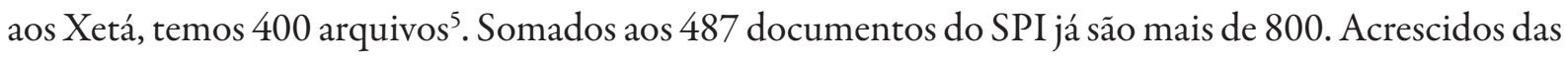
mais de 60 matérias jornalísticas sobre o grupo (cf. Leite 2019), alcançamos sem sobressaltos a marca de 900 documentos. Somados tantos outros documentos de Kozák, entre os quais avolumam-se os registros fotográficos, a sugestão de 1 mil documentos que atestam a existência - seja física seja cultural - dos Xetá pode acabar sendo modesta. Trata-se de uma documentação superlativa, que exigirá ainda muitos esforços para ser devidamente explorada. Impossível não se assustar com o volume de docu-

5 Uma aluna de Iniciação Científica, Juliana Ertes, atualmente, pesquisa esse acervo. 
mentos existentes, sobretudo se se considera que se trata hoje de um grupo indígena desterrado e semterra, o que não necessariamente é a mesma coisa, embora seja ambas as coisas. O projeto do desterro, lá na década de 1950, objetivava inequivocamente encaminhá-los à extinção. Não tendo a extinção sido efetiva, tornaram-se índios sem-terra.

Voltando à documentação, conforme recentemente escreveram os pesquisadores Lúcio Tadeu Mota e Rosângela Faustino (Mota e Faustino 2018), da Universidade Estadual de Maringá:

Esse processo governamental de esbulho dos territórios Xetá no Noroeste do Paraná gerou uma considerável massa de documentos. Tem-se a documentação gerada por órgãos governamentais de estado em nível federal, estadual e municipal: Ministérios Federais e órgãos a eles ligados como o Serviço de Proteção aos Índios - SPI; documentos gerados nas Secretarias de Estado do Paraná envolvidas no processo de colonização da região; pronunciamentos de políticos na Assembleia Estadual do Paraná; documentos gerados em prefeituras e câmaras municipais das cidades criadas na região. Existe a documentação depositada em órgãos da justiça que foram geradas a partir de disputas judiciais relacionadas à questão da terra e da colonização da Serra dos Dourados. Há a documentação produzida por fontes históricas não oficiais, como: correspondências e registros fotográficos de pessoas que estavam nas zonas fronteiriças da frente de expansão, escritos de memorialistas regionais que descreveram a ocupação da região e a criação das vilas, distritos e cidades, e os noticiários jornalísticos que registraram os diversos eventos ali ocorridos.

Identifica-se também registros gerados por pesquisadores e cientistas que participaram, em várias missões, na Serra dos Dourados a partir de 1955, sendo muitos deles amplamente publicados e outros ainda não devidamente conhecidos e que constam de arquivos dos pesquisadores e/ou das instituiçôes que participaram dessas missóes.

Os pesquisadores mencionados, como antes nós próprios, referem-se a documentos em papel, mas há vários outros. Entre tantos, têm-se a coleção de miniaturas em resina confeccionadas pelos Xetá, no acervo de V. Kozak, no Museu Paranaense, que é composta de 139 itens. No Museu de Arqueologia e Etnologia da UFPR (MAE/UFPR) estão depositados 210 outros objetos elaborados pelos Xetá. Segundo Pérez Gil (2012:105), trata-se "de uma das mais variadas e bem documentadas coleções existentes".

Como se não bastassem os papéis e objetos, existem ainda horas de gravação de entrevistas realizadas com os Xetá retirados da Serra dos Dourados, bem como com os colonizadores da região, que compuseram a coleção do Projeto Memória Indígena (PMI), hoje depositada no Museu de Arqueologia e Etnologia da UFPR (Lima e Zilli 2020), realizado por Maria Lígia de Moura Pires, na década de 1980. De uma década depois, existem as gravações e imagens de entrevistas realizadas por Carmen Lúcia da Silva, durante o encaminhamento de seus estudos de mestrado e doutorado, formando um acervo audiovisual que está também depositado no Instituto Socioambiental (ISA), organização nãogovernamental que recentemente colaborou com a digitalização do material. Recuando no tempo, existem os filmes realizados por Vladimir Kozák, que se encontram sob a guarda, como herança jacente, do Museu Paranaense. Finalmente, cabe mencionar os registros audiovisuais realizados pela equipe liderada por Lúcio Tadeu Mota, da Universidade Estadual de Maringá. Sem sermos exaustivos, mencionamos esses registros audiovisuais, mas é seguro que existem outros não devidamente divulgados, catalogados ou publicizados. 
Dado o volume de documentos em papel, de objetos e gravações audiovisuais que compõem os acervos de museus, torna-se inevitável escrever que se tais objetos seguem preservados em nossos "sótãos, porões, baús, álbuns e museus" (Wagner 2014:87) não se deve esquecer que nessa história "nunca houve um monumento da cultura que não fosse também um monumento da barbárie" (Benjamin 1996: 225), donde se vê, sem que se possa "refletir sem horror" (idem: 225), que documentos não faltam para comprovar a retirada violenta dos Xetá da terra reivindicada.

Não faz muito tempo, a Justiça brasileira privilegiava os documentos escritos aos orais para comprovar a existência de um dado grupo indígena em alguma terra reivindicada (Paraíso 1994). O Marco Temporal, especialmente no caso Xetá, põe por terra qualquer comprovação documental tal como vigia outrora - a compreensão dos documentos escritos como provas jurídicas -, ao ponto de parecer nutrir um certo desprezo pelos eventos documentados. É incompreensível, se não mesmo inconcebível, que vivemos em um lugar em que se exalta os documentos, em que se os coleciona, ao mesmo tempo em que se despreza os fatos que revelam, como é o caso do reconhecimento da violência, do genocídio vivido pelos Xetá, e a reivindicação por terra que ocupa hoje sua luta .

De uma perspectiva xetá, não cabe mudar a regra do jogo com a luta em curso. Pode-se, de modo excessivamente trivial, simplesmente pensar que a abundância de arquivos documenta um destino trágico. Mais assertivamente, pode-se pensar que a documentação atesta, inequivocamente, a violência que alcançou o grupo como um todo e o esbulho de suas terras. As visitas contemporâneas das lideranças aos arquivos imagéticos e de cultura material disponíveis no Museu de Arqueologia e Etnologia da UFPR e no Museu Paranaense documentam não apenas seu desejo de pesquisarem o que se passou, mas seu interesse em reescreverem sua história. No que diz respeito ao acervo de cultura material, cabe notar como Dival, liderança moradora atualmente na Terra Indígena São Jerônimo, filho de Tikuen, está copiando o modelo dos colares existentes outrora em um trabalho que ele mesmo em algumas ocasiões denominou "pesquisa”. Quanto ao material linguístico, Suzamara, sobrinha de Dival, recentemente contatou a nós, pesquisadores da UFPR, no intuito de obter registros de áudio para que um parente, estudante indígena em uma universidade estadual, possa “se especializar na língua”.

Tal interesse da parte dos Xetá, diferentemente de como se deu entre a comunidade científica em meados do século passado, não é motivado por um "pessimismo sentimental" (Sahlins 1997) cuja preocupação fundamental seria a de salvaguardar os aspectos culturais de um povo que, conforme nos dizia uma reportagem antiga da revista Panorama, chegaria ao fim na medida em que perdesse “inexoravelmente sua língua e sua cultura” (Costa 1961). Ao contrário, a relevância destes materiais legados no passado diz respeito aos seus projetos de futuro, eles têm sido apropriados como "um meio de estabelecer um lugar para os vivos" (Certeau 2002: 103) ou, se preferir, como um meio de "retomar controle do próprio destino" (Sahlins 1997:46). Conforme Benedita, filha de Tikuen, anunciou diante das câmeras, no último encontro Xetá realizado em outubro de $2019^{7}$ : "hoje, por foto, filmagem, nós estamos cada vez mais conquistando nosso espaço".

6 O uso dos itáicos aqui quer destacar o uso nativo do termo.

7 Encontros anteriores entre os Xetá descendentes daqueles “tirados do mato" ocorreram em duas ocasióes anteriores: em 1994, na mesma Terra Indígena São Jerônimo, com apoio de antropólogas Kimiye Tommasino e Marcolina Carvalho, da Universidade Estadual de Londrina, e servidoras da FUNAI; e, pela segunda vez, em Curitiba, em 1996, a partir dos esforços da antropóloga Carmen Lúcia da Silva, então servidora da UFPR e mestranda na UFSC. 
O lugar que se apresenta como destino, neste caso, é a terra de onde foram retirados, no noroeste paranaense, sendo pela evocação de um retorno ao local que os Xetá articulam suas falas públicas. Chama a atenção que, neste mesmo evento que possibilitou o reencontro dos Xetá, os filhos e filhas de líderes antepassados produzam narrativas cujo desejo de justiça por tudo que foi a violência histórica por eles sofrida, toque recorrentemente em dois aspectos: a (re)união de parentes que foram forçosamente separados, e a volta à terra de onde foram compulsoriamente deslocados. Foi sobre isto que falou Indioara, filha de Tuca (tirado do mato), quando, com o rosto pintado com as marcas de seu povo, o "símbolo dos Xetá", como eles dizem, lembrou que se deve lutar para que possam viver todos "juntos de novo”. Na sequência da fala, Albert, filho de Indioara e hoje vice-cacique de Kakané Porã, aldeia localizada em Curitiba (cf. Batista 2012), situou a "terra" como prioridade da luta.

Ambas as falas aconteceram neste Encontro Xetá, realizado em 7 de setembro de 2019, dia em que na cidade de São Jerônimo da Serra, parte da sua população não-indígena desfilava em celebração à Independência do Estado Brasileiro. No dia anterior, no entanto, foram os indígenas que desfilaram na cidade, de modo que na ocasião, os Xetá não hesitaram em corrigir uma autoridade local que, em posse da palavra, exaltou no microfone a "descoberta do Brasil por Pedro Alvares Cabral", quando, conforme me contava Suzamara, antes dos brancos “os índios já estavam aqui”. Ao seu modo, ela, e também seu filho, Renato, relatavam que a sua história não começa com o evento de aparecimento dos brancos, isto numa perspectiva temporal que seu avô, Tikuein, já compartilhava em suas narrativas: "Por isso que eu te digo que nossa história não começou depois dos brancos, tudo nosso começou antes deles" (Tikuein, apud Silva 2003:76). Assim, a correção que fazem opera por inversão, em que ao enunciado da inexistência de indígenas antes do Brasil, o que nos contam é que o Brasil é que não existia antes dos indígenas. Isto feito num dos maiores rituais de celebração do Estado nacional e ostentando nos rostos e nas roupas o símbolo Xetá cujo significado Dival, certa vez ensinou para as crianças na escola como sendo "Guerra".

São potentes as palavras dos Xetá contemporâneos - adultos, jovens e crianças, como Benedita, Albert e Renato, respectivamente - para falar do passado da primeira geração ascendente, de seus avós, pais, mães, tios e tias, tirados do mato. O "renitente esbulho" que a Justiça agora lhes exige se faz em narrativas sobre a violência sofrida nos corpos de seus parentes, e que se faz contínua em seus próprios corpos ainda desterrados.

É como se fosse possível dizer que voltar às antigas terras seria como reconectá-los a esse passado que ninguém viveu, ao mesmo tempo que os investir de um futuro que nunca tiveram. Nesse sentido, as lideranças são enfáticas em se indisporem com aqueles que os rotulam como um "grupo extinto ou em vias de extinção”" Estão vivos, afinal! Nas palavras de Claudemir, filho de Tikuen apresentado quando criança em uma das fotos, "estamos vivos, não somos apenas uma história" .

8 Há um volumoso número de trabalhos que registram os Xetá como um "povo em extinção", apesar dos autores, contraditoriamente, escreverem isso justamente em contato com membros do grupo, conforme apontaram Lima e Pacheco (2018). Entre tais autores constam os mencionados José Loureiro Fernandes e Vladimir Kozák, mas também Carlos Araújo Moreira Neto e o etnomusicólogo Desidério Aytai, entre outros.

9 Informação disponível em https://colecoesetnograficasxeta.com/, consultado em 22 de abril de 2019. 
De sua perspectiva, fazer Justiça de Transição seria garantir-lhes terras, uma providência que permitiria tirá-los desse limbo. Entre o passado e o futuro, o presente resta sempre como um tempo em suspensão. No passado e no futuro, naquela que é agora tida inequivocamente como sua terra originária, é que se põem a pensar como Xetás. A demarcação de suas terras - propriamente a devolução de suas terras -, sustentada a partir da farta documentação escrita, objectual e de potentes narrativas (Silva 1998, Pacheco 2018, Lima e Zilli 2020), se apresenta como a única alternativa para reparar ao menos parte dos males que lhes foram causados pelo Estado. De forma alguma isso seria a defesa de um anacronismo.

Edilene Coffaci de Lima é doutora em Antropologia pelo PPGAS/USP e professora do Departamento de Antropologia e do Programa de Pós-Graduação em Antropologia e Arqueologia da UFPR.

Gian Carlo Teixeira Leite é graduado em Ciências Sociais pela UFPR e mestrando em Antropologia na mesma instituição.

\section{REFERÊNCIAS BIBLIOGRÁFICAS}

BAPTISTA, Patrick. 2012. Indios, indios e indios: a aldeia Kakané Porã. Monografia. Graduação. Curitiba, PR: Universidade Federal do Paraná

BENJAMIN, Walter. 1996. “Sobre o conceito da História”. In: Obras Escolbidas. 1ª ed. São Paulo: Brasiliense, pp. 222-232.

CARNEIRO DA CUNHA, Manuela \& BARBOSA, Samuel (orgs.). 2018. Direitos Indigenas em Disputa. São Paulo: Editora Unesp.

CERTEAU, Michel de.2002. "O lugar do morto e o lugar do leitor". In: A Escrita da História. Rio de Janeiro: Forense Universitária. pp. 106-119.

CLASTRES, Pierre. 2014. “Do etnocídio”. In. Arqueologia da Violência. São Paulo: Cosac Naify. pp. 75-87.

CNV. 2014. Violação dos direitos humanos dos povos indígenas. In: Relatório da Comissão Nacional da Verdade. Brasília, v. 2, p. 197-256.

FERNANDES, José Loureiro.1958. “Os índios da Serra dos Dourados (Os Xetá)”. Anais da III Reunião Brasileira de Antropologia. Recife, 10 a 13 de fevereiro. pp. 27-46.

GONÇALVES, José H. Rollo. 1997. “A 'mística do pioneirismo', antídoto contra o socialismo: Bento Munhoz da Rocha Neto, a reforma agrária e o norte do Paraná nos anos 50 e 60”, Revista de História Regional 2(1):145-171.

LEITE, Gian Carlo T. 2019. "Do contato aos dias atuais: sete décadas de notícias sobre os Xetá da Serra dos Dourados”, Rev. Sociologias Plurais, 5(1): 343-367. 
LIMA, Edilene Coffaci \& PACHECO, Rafael. 2018. Os Xetá e seus acervos: memória histórica, política e afetiva (Paraná, Brasil). Comunicação apresentada no $56^{\circ}$ Congresso Internacional dos Americanistas, Salamanca (Espanha).

LIMA, Edilene \& ZILLI, Ana Clara F. 2020. "Fragmentos da história: os Xetá no Projeto Memória Indígena”. Sociologias Plurais, 6(1): 135-158.

MOTA, Lúcio Tadeu. 2013. Os Xetá do vale do rio Ivaí - 1840-1920. Maringá: EDUEM.

MOTA, Lúcio Tadeu \& FAUSTINO, Rosângela. 2018. O SPI e os Xetá na Serra dos Dourados - PR. Acervo documental 1948 a 1967. Maringá: EDUEM.

PACHECO, Rafael. 2018. Os Xetá e suas histórias: memória, estética e luta desde o exílio. Dissertação. Mestrado. Curitiba, PR: PPGA/UFPR.

PARAÍSO, Maria Hilda B. 1994. "Reflexões sobre fontes orais e escritas na elaboração de laudos periciais”. In: SILVA, Orlando Sampaio et al. (orgs.). Perícias antropológicas em processos judiciais. Florianópolis: Editora da UFSC, p. 41-52.

PÉREZ GIL, Laura. (2012). “O acervo etnográfico do MAE-UFPR”. In: M. Xavier Cury, C. Mello Vasconcellos \& J. Montero Ortiz (orgs.). Questôes indigenas e museus: debates e possibilidades. São Paulo: ACAM Portinari: Museu de Arqueologia e Etnologia da Universidade de São Paulo. p. 103112.

SAHLINS, Marshall. 1997. "O pessimismo sentimental e a experiência etnográfica: porque a cultura não é um objeto em via de extinção". Mana - Estudos de Antropologia Social do Museu Nacional. 3(1).

SILVA, Carmen Lúcia. 2003. Em busca da sociedade perdida: o trabalho da memória Xetá. Doutorado. Tese. Brasília, DF: PPGAS/Universidade de Brasília.

SILVA, Carmen Lúcia. 1998. Os Xetá: sobreviventes do exterminio. Dissertação de Mestrado. Florianópolis, SC: PPGAS/ Universidade Federal de Santa Catarina.

SOUZA, Jurema Machado. 2017. "Remoções, dispersões e reconfigurações étnico-territoriais entre os Pataxó Hãhãhãi”, Mediações 22(2): 99-124.

WAGNER, Roy. 2014. "A cultura como criatividade". In: A invenção da cultura. São Paulo: Cosac Naify, pp. 69-107.

ZILLI, Ana Clara. 2018. Os Xetá no acervo do Projeto Memória Indígena (1985-1989) do Museu de Arqueologia e Etnologia da UFPR. Monografia de Conclusão do curso de Ciências Sociais. Universidade Federal do Paraná.

\section{Documentação Jornalística}

CATALDI, Luis. 1951. "O General Café assume o comando econômico do Paraná”. Revista da Guaira - Curitiba.

COSTA, Samuel Guimarães. 1961. “Os sobreviventes da Idade da Pedra”. Revista Panorama, Curitiba - PR, ano VII, n.11, pp. 20-26.

Nova ação de despejo no oeste do PR: desta vez, Itaipu tenta desalojar os Avá-Guarani da aldeia Yva Renda. Conselho Indigenista Missionário - CIMI, 4 abr. 2019. Disponível em: https://bit. ly/35ukabq Acesso em: 24/11/2019.

UBIRATAN, Paulo. 1994. "Revolta marcada com uma cruz". Folha de Londrina, 06 de maio. 


\title{
JUSTIÇA DE TRANSIÇÃO E OS XETÁ: SEM ANACRONISMOS
}

Resumo: Em meados do século XX, o povo indígena Xetá, falantes de língua tupi, quase sucumbiram à violência contra eles perpetrada no contexto de avanço da colonização cafeeira rumo ao noroeste do Paraná, onde foram oficialmente contatados. O confisco de terras, deslocamento territorial forçado e a drástica redução populacional a qual foram submetidos, tal como relatado na Comissão Nacional da Verdade, situa o caso como sendo de genocídio realizado pelo próprio Estado. Atualmente, vivendo em territórios alheios, os Xetá almejam o retorno às suas antigas terras. No entanto, tal território resta apenas identificado e contestado, de modo que sua efetiva demarcação não parece prevista para o futuro próximo. A tese do Marco Temporal, ao não reconhecer a existência do grupo, tem sido o maior obstáculo político para realização deste retorno. Tese arbitrária quando se observa que uma imensa quantidade de documentos atestam o seu oposto, a saber, existência dos Xetá.

Palavras-chave: Xetá; Genocídio; Marco Temporal; Justiça de Transição.

\section{TRANSITIONAL JUSTICE AND THE XETÁ: NO ANACRONISMS}

\begin{abstract}
In the mid-twentieth century, the indigenous Xetá people, speakers of the Tupi language, almost succumbed to the violence against them perpetrated in the context of advancing coffee colonization towards northwestern Paraná, where they were officially contacted. The confiscation of land, forced territorial displacement and the drastic population reduction to which they were subjected, as reported by the National Truth Commission, situates the case as a genocide carried out by the State itself. Currently, living in foreign territories, the Xetá aim to return to their former lands. However, such territory remains only identified and contested, so that its effective demarcation does not seem to be foreseen for the near future. The Marco Temporal thesis, by not recognizing the existence of the group, has been the biggest political obstacle to achieving this return. Arbitrary thesis when it is observed that an immense amount of documents attest to its opposite, namely, the existence of the Xetá.
\end{abstract}

Keywords: Xetá; Genocide; Temporal Framework; Transitional Justice.

RECEBIDO: $01 / 12 / 2019$

APROVADO: $01 / 02 / 2020$ 